\title{
Mídia, Sociedade, Educação E A Democratização Dos Meios De Comunicação
}

\section{Media, Society, Education And The Democratization Of The Communication.}

João Carlos Lopes Fernandes ${ }^{1}$, Mônica Maria Martins de Souza²

\begin{abstract}
1.João Carlos Lopes Fernandes é bacharel em Ciências da Computação, Mestre em Engenharia de Computação e Doutor em Engenharia Biomédica na área de Tecnologias Computacionais. Coordenador do curso Análise e Desenvolvimento de Sistemas da Faculdade de Tecnologia de São Caetano do Sul, professor associado do Instituto Mauá de Tecnologia, professor e autor da pós-graduação da Unyleya, pesquisador da Faculdade ENIAC.
\end{abstract}

2.Mônica Maria Martins de Souza é Psicóloga Doutora em Comunicação e Semiótica, Mestre em Administração, Especialista em RH, Docência e Tecnologia educacional. Professora de Pós-graduação do Mackenzie, UNIP, ENIAC. Coordenadora e organizadora de seminários e Editora de Anais e revista acadêmica da Campos Salles e ENIAC.

\section{Resumo}

A sociedade atualmente vive em torno das mídias, a cada dia uma nova tecnologia ou atualização tecnológica acontece. Aproveitando-se desta tendência, os educadores podem utiliza-las como apoio educacional. Educar com mídias desde anos 70 já é vista como um novo campo do saber. No Brasil, os meios de comunicação em massa não se preocupam com a educação, estes grupos empresariais privados, possuem interesses exclusivamente financeiros.

Palavras-chave: Mídias, sociedade, educação, democratização, comunicação.

\begin{abstract}
The company currently lives around the media, every day a new technology or technological update happens. Taking advantage of this trend, educators can use them as educational support. Educating with media since the 70 is already seen as a new field of knowledge. In Brazil, the mass media do not care about education, these private business groups, have exclusively financial interests.
\end{abstract}

Keywords: Media, society, education, democratization, communication. 


\section{Introdução}

As reflexões sobre o tema, tem o objetivo de compreender o movimento da aproximação da educação e da mídia e da dependência que se estabelece entre elas. Há várias décadas, a integração destas vem se confluindo à medida que se constata a sua influência na formação do sujeito contemporâneo. Depois dos anos 70 o rápido desenvolvimento das tecnologias de informação e comunicação criou a necessidade de se explorar o tema e atualizar técnicas e informações. A complexidade atual deriva do descobrimento em 1945, no pós guerra, do Electronic Numerical Integrator And Computer ENIAC - Computador e Integrador Numérico Eletrônico. Foi desenvolvido a partir de 1940, pelos pesquisadores norte-americanos da Electronic Control Company: John Eckert e John Mauchly, que revelavam ao mundo o primeiro computador eletrônico digital de larga escala que em sua origem ocupava o espaço equivalente a um campo de futebol de salão.

\section{A metodologia utilizada para} compreender como os educadores utilizam a tecnologia como apoio educacional é pesquisa bibliográfica e a pesquisa eletrônica, com observação in loco nos laboratórios e na metodologia utilizada nas salas de aulas atuais de diversas instituições de ensino e nas empresas de desenvolvimento tecnológico.

A justificativa da pesquisa é analisar a criação das novas tecnologias e da sua atualização e a sua influencia na educação em parceria com as mídias desde anos 70, descortinando um novo campo do saber no Brasil e no mundo.

A hipótese é que a aplicação da tecnologia na educação contribui com o desenvolvimento de ambas, gerando ganhos para as duas ciências e contribuindo com toda a sociedade que atualmente vive em torno das mídias. Mas que no Brasil, os meios de comunicação em massa não se preocupam com a educação, pois os grupos empresariais privados possuem interesses exclusivamente financeiros e não sociais.

O referencial teórico utilizado nesta investigação envolve os diversos autores que discutem o tema educação, tecnologia e midia como: ADORNO, Theodor W. Adorno1999. DORIGONIL, Gilza Maria Leite, 2015. THOMPSON, John Brookshire (2015). THOMPSON (2008), que discute Mídia e a Modernidade entre outros. 


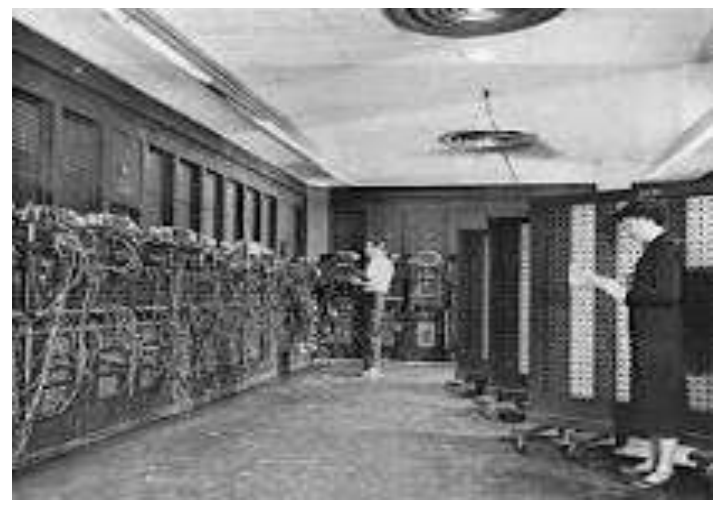

Figura 1 - ENIAC, primeiro computador do mundo.

Fonte: $\quad$ https://tecnoblog.net/.../eniac-primeirocomputador-do-mundo.

Nesta época, a concentração econômica e administrativa aliada ao desenvolvimento tecnológico estabelecia semelhança estrutural ao cinema, rádio e revistas. A educação para as mídias como perspectivas de um novo campo de saber e de intervenção vem se desenvolvendo a partir dos anos de 1970 - conhecida como era da tecnologia e que gerou a era atual, que é a era do conhecimento. No mundo inteiro a educação para as mídias tem o objetivo de formar usuários ativos, criativos, críticos de todas as tecnologias de informação e comunicação (DORIGONIL, 2015).

Atualmente, as mídias apresentam questões que causam polêmicas, e em contra partida muita reflexão. Isso se deve aos efeitos e fenômenos que impactam nossa sociedade e com isso são os responsáveis pelo nascimento dos estudos da comunicação. As mídias sociais têm em nosso cotidiano um papel fundamental na sociedade moderna, além de informar elas têm a capacidade de encurtar distancias, onde por si transformam-se em meios que a sociedade midiatizada, como uma referência de modelo de socialização. Uma sociedade está em busca constante de atualização e as mídias fazem com que este processo seja construído durante determinados momentos. Tudo que a mídia projeta, atrai sempre um determinado número de pessoas, que compartilham seus valores e cultura.

\section{Aplicação Das Tecnologias Da}

\section{Informação E Comunicação Na Escola}

Para efetivar a aplicação das tecnologias da informação e comunicação na escola, após a constatação de sua importância e necessidade, é preciso criar os mecanismos que possibilitem integração à educação evitando o deslumbramento ou o uso indiscriminado da tecnologia. É imprescindível verificar a parte pedagógica em detrimento das virtualidades técnicas, fugindo de um discurso ideológico procedente da indústria cultural. (Dorigonil, 2015)

Um detalhe importante que deve ser levado em consideração é que a TV e o rádio conseguem atender todas as regiões do país, transmitindo notícias, cultura e conhecimento. A comunicação através da TV ou Rádio sempre será um mediador para a produção do conhecimento, onde um dos maiores reflexos acontece no contexto social. Quando o modelo de rádio foi implantado no Brasil na década de 20, optou-se pelo modelo comercial e não educacional. A busca por uma sociedade 
midiatizada visa principalmente o campo do consumo, que necessita ser instigado para sua própria sobrevivência. Normalmente os meios de comunicação refletem os pontos fracos da sociedade e muitas vezes a insatisfação com os problemas ligados a educação, saúde, infraestrutura e desigualdade social.

\section{O Discurso Midiático}

O discurso midiático muitas vezes manipula as pessoas, "nem tudo que é transmitido é verdade" e tem fé publica. O avanço da tecnologia foi determinante para o avanço da mídia que, mostra seu impacto social. Este impacto provém do processo de construção e manutenção continuada "lavagem cerebral" através de suas interações e opiniões pessoais. Nada se constrói sem coletividade, atualmente quase tudo é influenciado pela midiatização.

Segundo Chomsky, podemos esperar aprender algo sobre a natureza humana; algo significativo, se de fato "a linguagem" é verdadeiramente representativa e a mais notável característica das espécies. Notemos ainda que não é despropositado supor que o estudo desta realização humana, a sua capacidade de falar e compreender uma língua pode servir de modelo sugestivo de investigação noutros domínios da intuição e ação humanas que não se apresentam tão convidativos à observação direta.
Segundo Thompson, o conceito de ideologia tem sido considerado, predominantemente, de duas maneiras: ou é tido como um sistema de ideias (os 'ismos' socialismo, liberalismo etc.), ou é considerado muito ambíguo e, por isso, abandonado. Para recuperar esse campo essencial às suas proposições, estuda as várias fases do conceito e seus contextos teóricos e sócio-históricos.

A mídia-educação é um conceito que se traduz em um trabalho educativo desenvolvido com o apoio das mídias sociais. Nele são estudadas as linguagens como ferramentas de apoio às atividades didáticas. Elas podem auxiliar muito a produção de conteúdos para sala de aula e, também, a educação à distância, quando o meio se transforma no ambiente em que os processos de ensino-aprendizagem ocorrem.

Ela também vem se consolidando ao longo dos anos como uma reflexão metodológica nos modos de educar. Ela possui basicamente três dimensões:

a) a interdisciplinar na interseção das ciências da educação e comunicação;

b) a disciplina curricular ou no eixo transversal;

c) a prática social e cultural em diferentes contextos escolares.

Sendo assim se pode entender que ela é uma área do saber e de intervenção em diversos 
contextos. Diversos países já trabalhavam com as mídias mesmo antes de uma definição pedagogicamente a seu respeito. O "educar" para o uso das mídias, aos poucos foi se transformando em educar através das mídias. A primeira definição oficial do conceito de "Media Education" foi apresentada na França pelo Conselho Internacional de Cinema e Televisão (CICT), órgão ligado a UNESCO, em junho de 1973, e se referia ao estudo e aprendizagem dos modernos meios de comunicação como disciplina autônoma no âmbito da teoria e prática pedagógica, e reconhecia a escola como o lugar ideal para utilização das mídias educacionais. Em 1979, o mesmo conselho ampliou o campo de intervenção das mídias como processos culturais e sociais, e consequentemente seu conceito, o especificando como prática social e cultural. Como não existe educação sem comunicação, o papel da mídiaeducação é propiciar às crianças, aos jovens e aos professores a alfabetização ou letramento midiático. A educação se relaciona aos objetivos da mídia-educação com o seu envolvimento nas escolas e na formação inicial dos professores como em outros âmbitos e contextos formativos. (Tadeu, 2015)

Segundo Bévort, a mídia-educação é parte essencial dos processos de socialização das novas gerações, mas não apenas, pois deve incluir também populações adultas, numa concepção de educação ao longo da vida. Tratase de um elemento essencial dos processos de produção, reprodução e transmissão da cultura, pois as mídias fazem parte da cultura contemporânea e nela desempenham papéis cada vez mais importantes, sua apropriação crítica e criativa, sendo, pois, imprescindível para o exercício da cidadania.

Foi no século 21, quando o futuro já chegou, observamos novos modos de socialização e mediações inéditas, decorrentes de artefatos técnicos extremamente sofisticados (como por exemplo, a realidade virtual) que subvertem radicalmente as formas $e$ as instituições de socialização estabelecidas: as crianças aprendem sozinhas (“autodidaxia”), lidando com máquinas "inteligentes" e "interativas", conteúdos, formas e normas que a instituição escolar, despreparada, mal equipada e desprestigiada, nem sempre aprova e raramente desenvolve. A mediatização generalizada da informação tende a vulgarizar a ciência, vender gadgets tecnológicos, estabelecer e divulgar a agenda política, além de construir o imaginário coletivo com seus rituais planetários (Belloni, 2009).

\section{Modelos De Comunicação E Interação}

Segundo Thompson, em virtude de uma série de inovações técnicas associadas à invenção da impressão e, consequentemente, à codificação elétrica da informação, as formas simbólicas começaram a ser produzidas, reproduzidas e distribuídas numa escala sem precedentes. Os modelos de comunicação e interação se transformaram de maneira profunda 
e irreversível. Estas mudanças, que incluem o que chamaríamos de 'mediação da cultura', tinham uma base cultural muito clara: o desenvolvimento das organizações da mídia que apareceram primeiramente na segunda metade do século XV e foram expandindo suas atividades a partir de então.

No Brasil, a exploração dos órgãos de comunicação de massa é feita por grupos empresariais privados, com interesses exclusivamente financeiros. As eleições mais importantes que aconteceram no Brasil em 2014 sofreram grande influência da propaganda veiculada pela imprensa, pelo rádio e, sobretudo, pela televisão. Quando a maioria das noticias são passadas de modo depreciativo em relação ao complexo político-empresarial dominante, o debate público é falseado, com a utilização da técnica que os norte-americanos denominam agenda-setting; ou seja, passa-se a noticiar outras matérias, em geral sensacionalistas, para desviar a atenção pública do assunto incômodo. Em pouco tempo, os fatos desabonadores para a classe dirigente são esquecidos (Governo, 2000).

Para que o povo possa ter assegurado o seu direito fundamental à informação (Constituição Federal, art. $5^{\circ}$ - XIV), é indispensável construir um sistema institucional que impeça ou, pelo menos, dificulte seriamente a monopolização dos meios de comunicação de massa pela classe empresarial. Para tanto, é preciso mudar o tipo de licenciamento dos veículos de comunicação que atualmente são meramente capitalistas. Sendo assim os meios de comunicação além de se tornarem imparciais, deveriam dedicar parte de sua programação a educação e cultura (Valente, 2015).

Atualmente os meios de comunicação no Brasil, passam por uma transição ideológica, as noticias buscam apresentar a realidade "nua e crua", desta forma existe uma forte tendência política em implantar a censura às mídias, isto não é democratizar as mídias, mas cercear o direito de expressão (Moreno, 2015). A TV brasileira possui algumas iniciativas voltadas a educação e cultura e vale a pena salientar o telecurso, o canal Futura, a rede cultura dentre outras que possuem em sua programação momentos culturais educacionais, mas que são insuficientes para atender a demanda da população.

A Internet está crescendo de forma exponencial nos últimos anos. Ela é um meio que apresenta várias soluções que podem ser utilizadas na educação e também possui a capacidade de homogeneizar a cultura de forma geral. Como canal de construção do conhecimento a Internet tem a capacidade de transformar e disseminar as informações entre alunos e professores. A Internet não leva em consideração as distâncias físicas e temporais, desta forma consegue comunicar-se em tempo real com alunos e professores do mundo inteiro. Outra vantagem é que ela consegue trabalhar 
com grande volume de armazenamento de dados e quando tratados conseguem produzir o conhecimento de forma rápida (Dorigoni, 2015). Desta forma das tecnologias de comunicação atuais a Internet é um grande aliado à educação através de cursos online gratuitos, buscadores de conteúdo, tradutores e ferramentas especificas para rede social, como "facebook".

Mesmo com tantas vantagens elencadas para a utilização da Internet como ferramenta educacional alguns cuidados devem ser tomados, pois com a facilidade de acesso muitas pessoas se aproveitam e realizam o chamado "recorta e cola", sem referenciar as fontes e muitas vezes até de forma inconsistente.

\section{Considerações Finais}

A utilização de mídias na educação deve ser incentiva tanto em cursos presencias como na modalidade à distância, pois ela aproxima alunos e professores. A Internet dentre as soluções de disseminação do conhecimento é uma das mídias que apresenta mais recursos e facilidades, mas deve existir um bom planejamento e controle por parte do professor, para que a ferramenta não se tornar uma armadilha.

O uso da TV e do rádio também devem ser insensitivas, pois estes dois meios de comunicação são muito ricos em conteúdo, seja em um projeto de TV ou radio escola, radio WEB ou até mesmo sua utilização de maneira convencional (programação da TV e do Radio).
Referências

BELLONI, Maria Luiza. O que é mídiaeducação. Campinas: Autores Associados, 2001.

BÉVORT, Evelyne; BELLONI, Maria Luiza. Mídia-educação: conceitos. História e perspectivas. Educ. Soc., Campinas, vol. 30, n. 109, p. 1081-1102, set./dez. 2009

CHOMSKY, Noam. Linguagem e responsabilidade. São Paulo: JSN Editora, 2007.

CHOMSKY1, Noam. As 10 Estratégias de Manipulação Midiática. Disponível <http:// www.institutojoaogoulart.org.br/noticia.php? Id $=1861>$ Acesso 10/02/2015

DORIGONIL, Gilza Maria Leite; SILVA, João Carlos da. Mídia e Educação: o uso das novas tecnologias no espaço escolar. Disponível <www.diaadiaeducacao.pr.gov.br/portals/pde/ arquivos/1170-2.pdf> $\underline{\text { http://maratavarespsi }}$ ctics. pbworks.com/w/file/fetch/74430536/31170-2. pdf. Acesso 10/02/2015.

GOVERNO. A Democratização dos Meios de Comunicação de Massa. (2000) Disponível http://www.escoladegoverno.org.br/artigos/21 2-democratizacao-midia> Acesso 10/02/2015. 
MORENO, Rachel. Controle social não é

censura. Disponível <http://www.Observa toriodaimprensa.com.br/

news/view/_ed750_controle_social_nao_e_ce nsura $>$ acesso 10/02/2015.

TADEU, Marcus. Mídia e Educação em debate.

Disponível

$<$ http://www.revistapontocom.org.

br/entrevistas/midiaeducacao-em-debate-5> acesso 10/02/2015.

THOMPSON, John Brookshire. A Mídia e a

Modernidade. Petrópolis: Vozes, 2008.

VALENTE, Jonas. Regulação da mídia não tem nada a ver com censura. Disponível $<$ http://www.observatoriodaimprensa.com.br/ news/view/_ed712_regulacao_da_midia_nao_t em_nada_a_ver_com_censura $>\quad$ acesso 10/02/2015

ADORNO, Theodor W. Adorno1999. DORIGONIL, Gilza Maria Leite, 2015. THOMPSON, John Brookshire (2015).

ADORNO, Theodor W. Adorno: vida e obra. Coleção Os Pensadores. São Paulo: Editora Nova Cultura Ltda., 1999.

ALVES, Gilberto Luiz. A produção da escola pública contemporânea. Campinas, SP: Autores Associados, 2005.
BACON, Francis. Novum organum ou verdadeiras indicações acerca da interpretação da natureza. 2.ed. São Paulo: Victor Civita, 1979.

BELLONI, Maria Luiza. O que é MídiaEducaçao. 2.ed. Campinas, SP: Autores Associados, 2005. (Coleção polêmica do nosso tempo, 78).

FERNANDEZ, Alicia. Os idiomas do aprender: análise de modalidades ensinantes em famílias, escolas e meios de comunicação. Porto Alegre: Artes Médicas, 1991.

FERRETTI, Celso João (org). Novas tecnologias, trabalhos e educação. Petrópolis: RJ, Vozes, 1994.

FRIGOTTOO, Gaudêncio. Artigo: Fundamentos Científicos e técnicos da relação trabalho e educação no Brasil de hoje. 17 GARCIA, Paulo Sérgio. A Internet como nova mídia na educação. Disponível em:. Acesso em: 21 dez.2007.

KALINKE, Marco Aurélio. Para não ser um professor do século passado. Curitiba: Gráfica Expoente, 1999. LEITE, Márcia. A Influência da Mídia Educação. Revista Mídia e Educação. Disponível em:. Acesso em: 15 dez./2000

NOSELLA, Paolo. Trabalho e Perspectivas de Formação dos Trabalhadores: para além de uma formação politécnica. Disponível em: 
http://PDE.pr.gov.br. Acesso em: 20 nov./2007 PATTO, Maria Helena Souza. A produção do fracasso escolar: histórias de submissão e rebeldia. São Paulo: Casa do Psicólogo, 1999. PEDROSO, Leda Aparecida; BERTONI, Lucia Mara. Indústria Cultural e Educação: reflexões críticas. Araraquara: JM, 2002.

PRETTTO, Nelson. PINTO, Cláudio da Costa. Tecnologias e Novas educações. Revista Brasileira de Educação, v.11, n. 31, jan/abr. 2006.

PUCCI, Bruno; MEDEIROS, Fabiana S.F. Indústria Cultural e Educação. In BERTONI, Luci Mara: Vaidergorn, José. Indústria Cultural e educação (ensaios, pesquisas, formação). 1o ed, Araquara: JM, 2003

PUCCI, Bruno (org). Teoria Crítica e Educação: a questão da formação Cultural na Escola de Frankfurt. Petrópolis, RJ: Vozes; São Carlos, SP: EDUFISCAR, 1994, 2a edição

SACRISTÁN, J. Gimeno; GÓMEZ, A.I. Pérez. Compreender e transformar o Ensino. Porto Alegre: Artmed, 1998.

TOSCHI, Mirza Seabra; RODRIGUES, Maria Emília de Castro. Infovias e Educação. Revista Educação e Pesquisa, São Paulo, v.29, no 2, jul/dez. 2003.
VIGOTSKI, L. S.; LURIA, A. R.; LEONTIEV, A. N. Linguagem, desenvolvimento e Aprendizagem. São Paulo: Ícone, 2006.

http://maratavarespsictics.pbworks.com/w/fil e/fetch/74430536/3-1170-2.pdf. 